\title{
ANALISA KINERJA KEUANGAN BTM BINA MASYARAKAT UTAMA DI BANDAR LAMPUNG
}

\author{
Ruslaini1), Moh. Fakhrurozi2) \\ Universitas Muhammadiyah Lampung ${ }^{1}$ \\ ruslaini@umlampung.ac.id \\ Universitas Muhammadiyah Lampung 2 \\ fakhrurozi@umlampung.ac.id
}

\begin{abstract}
BTM Bina masyarakat utama (BiMU) is one of the businesses in the financial sector. The research methods used namely description and qualitative. The data based on the results of the study and annual reports of members. Economic business charityare one of the organizations' efforts for gaining of economy field goal, to ensure and to establish the religion of Islam in order to promote the economic conditions of the community, so the society can be prosperous that is blessed by God. BMT BiMU Bandar Lampung services of finance are dominated in the trade sector, it reach out $80 \%$ of the 14,299 members and they are in traditional markets especially at productive businesses; BTM BiMU Bandar Lampung has not been able to fulfill the minimum needs of the liquidity in Eid holiday.Financial Performance of BTM BiMU as follows: Current ratio, leverage ratio, profitability ratio result, they are not good enough. Based on the financial performance over 2017, it can be seen that the current ratio is less than 100 , the leverage ratio showed that the value $>80$ so that the debt still dominated and ROA and ROE showed that less than $1 \%$, it indicates the lowest profit.
\end{abstract}

Keywords: Performance, Financial Ratio

\section{PENDAHULUAN}

Amal usaha bidang ekonomi bertujuan untuk membimbing masyarakat kearah perbaikan dan mengembangkan ekonomi sesuai dengan ajaran Islam serta untuk meningkatkan kualitas pengelolaan amal usaha Muhammadiyah. Amal usaha Muhammadiyah di Bandar Lampung bidang ekonomi terutama keuangan syari'ah antara lain BTM Bina Masyarakat Utama (BiMU), Puskopsyah BTM serta BMT-BMT lainnya yang dikelola oleh kader Muhammadiyah. Sasaran program pelayanan terutama sektor riilyaitu pelaku usahamikro dan kecil.

Hal ini merupakan kajian yang penting bagi persyarikatan Muhammadiyah, sebab Muhammadiyah bukan sebatas ormas keagamaan akan tetapiormas agama dan sosial. Dalam Anggaran Rumah Tangga Muhammadiyah pasal 3, dijelaskan bahwa usaha Muhammadiyah di bidang ekonomi adalah: "memajukan perekonomian dan kewirausahaan ke arah perbaikan hidup yang berkualitas. Memajukan perekonomian dan kewirausahaan dapat dicapai dengan berbagai strategi dan taktik atau sejak dari teori sampai praktik. Sasaran yang hendak dicapai dari usaha dibidang ekonomi adalah perbaikan hidup yang berkualitas.

BTM BiMU merupakan amal usaha Muhammadiyah yang mandiri dalam bidang ekonomi. Didirikan oleh Majelis Ekonomi dan Kewirausahaan Pimpinan Wilayah Muhammadiyah (PWM) Provinsi Lampung pada tahun 2004 dengan nama Koperasi Syari'ah BTM Bandar Lampung, namun sesuai dengan peraturan Kemenkop, pada Rapat Anggota Tahunan Tahun Buku (RAT TB) 2015 berubah menjadi KSPPS BTM BiMU 
yaitu Koperasi Simpan Pinjam Pembiayaan Syari’ah Baitut Tamwil Muhammadiyah Bina Masyarakat Utama.

BTM melakukan kegiatan pengembangan usaha produktif dan investasi dalam meningkatkan kesejahteraan pengusaha mikro melalui kegiatan pembiayaan dan menabung. Sebagai amal usaha, BTM tumbuh dan berkembang dibawah binaan PWM Lampung melalui Majelis Ekonomi dan Kewirausahaan PWM Lampung. Pada awal berdirinya, BTM mendapat pinjaman dana dari Majelis Ekonomi Muhammadiyah Wilayah Lampung sebesar Rp. 2.000.000,- (dua juta rupiah). BTM menjalankan fungsinya sebagai lembaga keuangan yang bergerak dalam bidang jasa keuangan khususnya pembiayaan usaha yang beroperasi berdasarkan prinsip-prinsip syari'ah. Kegiatan pembiayaan pertama kali diberikan kepada pedagang-pedagang kecil yang ada di pasar tradisional Way Halim, Bandar Lampung. Keberadaan BTM diharapkan dapat menjadi pusat pengelolaan keuangan Muhammadiyah dan ujung tombak da'wah bil häl Muhammadiyah Lampung.

Penelitian ini bertujuan untuk menganalisa kinerja keuangan BTM BiMU di Kota Bandar Lampung. Sumber data berdomisili dan atau bekerja diwilayah kota Bandar Lampung, provinsi Lampung.

\section{LITERATUR REVIEW DAN PENGEMBANGAN HIPOTESIS}

Amal usaha ekonomi adalah salah satu usaha persyarikatan untuk mencapai maksud dan tujuan persyarikatan dibidang ekonomi, yakni menegakkan dan menjunjung tinggi agama Islam serta memakmurkan kondisi perekonomian masyarakat, sehingga terwujud masyarakat berpenghasilan yang diridlai Allah SWT.

Amal usaha yang langsung berhubungan dengan masyarakat adalah Koperasi Syariah Baitut Tamwil Muhammadiyah (BTM) Bandar Lampung, karena merupakan koperasi primer. BTM BiMU berbadan hukum No.024/BH/DKPKPM/X/2005 dengan akte notaris Budi Kristiyanto no. 11 Tanggal 09 Agustus 2005.Dengan akte perubahan anggaran dasar no.78 tanggal 16 Desember 2010 dan no. 02 tanggal 01 Juni 2011.

Visi BTM BiMU adalah menjadi koperasi syari'ah pilihan utama masyarakat dalam mendukung gerakan dakwah ekonomi Muhammadiyah. Adapun misi BTM BiMU adalah:

1. Mensejahterakan anggota pada khususnya dan masyarakat pada umumnya dengan sistem ekonomi syari'ah;

2. Menyajikankan produk-produk transaksi syari'ah yang sesuai dengan kebutuhan anggota;

3. Memberikan pelayanan terbaik, transparan, dan akuntabel kepada anggota;

4. Melahirkan tenaga-tenaga profesional di bidang lembaga keuangan syari'ah, mampu berkompetisi dan berakhlakul karimah;

5. Mengembangkan kerjasama yang baik dengan seluruh pemangku kepentingan (stakeholder) dalam meningkatkan perekonomian ummat;

6. Mendasarkan setiap aktivitas pada tata kelola yang akuntabel.

BTM BiMU terus berkembang dan pada tahun 2017 telah memiliki beberapa cabang

Ahmad Dahlan dan kantor kas, cabang dan beberapa kantor kas yang tersebar di pulau Jawa dan Sumatera:

\section{METODE PENELITIAN}

Waktu penelitian dan penyusunan laporan penelitian ini dilakukan selama6 (enam) bulan di wilayah kota Bandar Lampung. Secara geografis Kota Bandar Lampung terletak pada $5^{0} 20^{\prime}$ sampai dengan $5^{0} 30^{\prime}$ lintang selatan dan $105^{\circ} 28^{\prime}$ sampai dengan $105^{\circ} 37^{\prime}$ bujur 
timur. Letak tersebut berada pada Teluk Lampung diujung selatan pulau Sumatera.

Penelitian ini bersifat deskriptif kualitatif, yaitu menggambarkan dan mendeskripsikan keadaan atau suatu objek kemudian menganalisisnya (Sumardi Suryabrata, 1990:1). Penelitian deskriptif dapat diartikan pula sebagai penelitian yang mempelajari masalah-masalah dalam masyarakat,serta tata cara dan situasi-situasi yang berlaku, termasuk hubungan-hubungan, kegiatan-kegiatan, sikap-sikap, pandangan-pandangan, serta proses yang sedang berlangsung dan pengaruh- pengaruh dari fenomena (M.Iqbal, 2002:14).

Kualitas hasil penelitian bergantung pada kualitas data yang digunakan, data yang baik harus memenuhi data-data yang akurat, relevan, uptodate. Data adalah kejadiankejadian khas yang dinyatakan sebagai fakta yang berwujud bagi pengukuran, sedangkan fakta adalah kejadian-kejadian dari suatu gejala sosial. Data kualitatif adalah data yang dinyatakan dalam bentuk kalimat atau uraian, dimana data ini mempunyai peranan untuk menjelaskan secara deskriptif suatu masalah. Data tersebut dibedakan berdasarkan sumbernya adalah: (Suliyanto, 2012: 225)

1. Data primer, yaitu data yang diperoleh secara langsung dari sumber pertama, melalui survei langsung kepada responden dengan wawancara dan observasi. Dengan responden berasal dari pelaku amal usaha dan pengguna pelayanan amal usaha.

2. Data sekunder, yaitu data yang diperoleh melalui orang lain atau dokumen, perguruan tinggi, perpustakaan dan lain sebagainya.

\section{HASIL PENELITIAN}

Perkembangan modal anggota 2016 sejumlah Rp. 1.184.526.071,- dan pada tahun 2017 menjadi Rp. 1.708.515.802,- atau naik sebesar 43\%, perkembangan tersebut dapat dilihat dari gambar 1:

Gambar 1

Perkembangan Modal Anggota

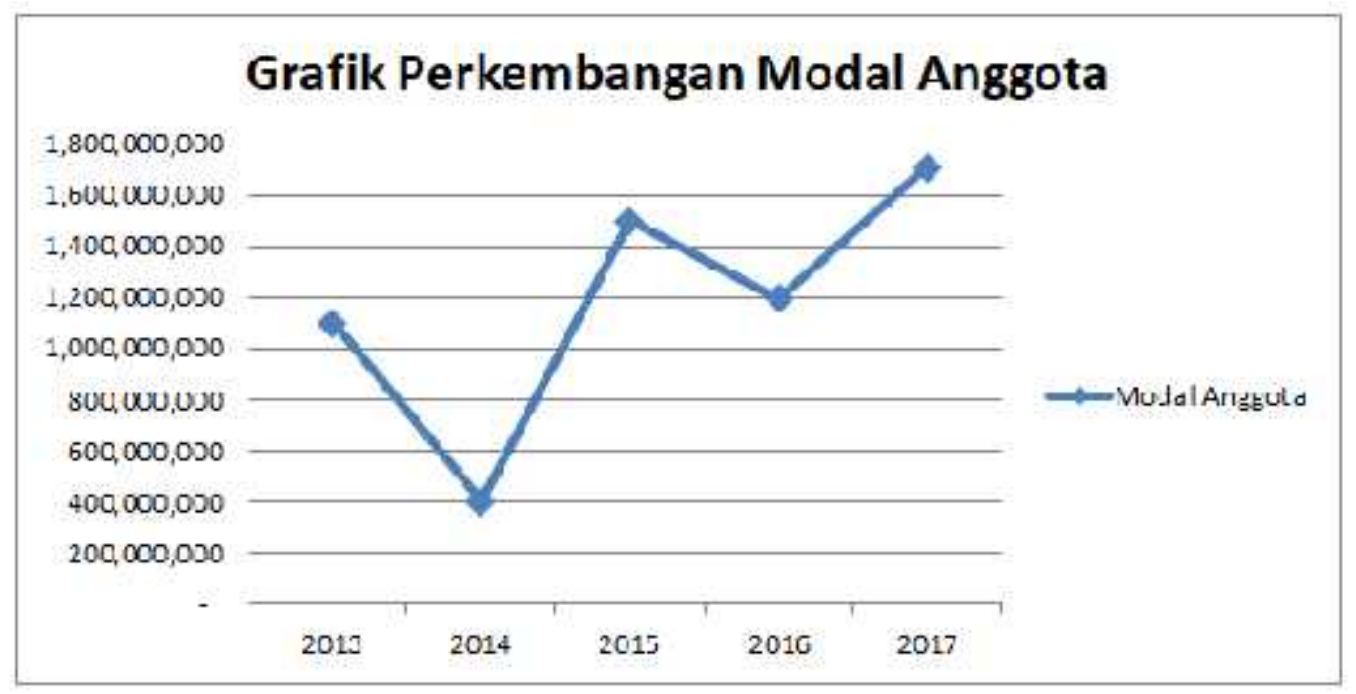

Dalam memberikan pelayanan pembiayaan, BTM BiMU menerapkan prinsipprinsip kehati-hatian dengan melakukan analisa pembiayaan. Hal ini dilakukan agar 
pembiayaan yang diberikan tepat sasaran dan aman bagi BTM BiMU. Prinsipnya setiap pembiayaan yang direalisasi disesuaikan dengan nilai obyek jaminan. Berdasarkan data yang ada, kondisi pembiayaan di BTM BiMU memiliki pembiayaan yang bermasalah/Non Performing Finance (NPF) sebesar 2,8\%.

Total penyaluran pembiayaan tahun 2016 sejumlah Rp. 12.117.044.699,- dan pada tahun 2017 menjadi sejumlah Rp. 48.483.891.061,- atau naik sebesar 300\%, perkembangan tersebut dapat dilihat dari gambar 2:

Gambar 2

Total Penyaluran Dana

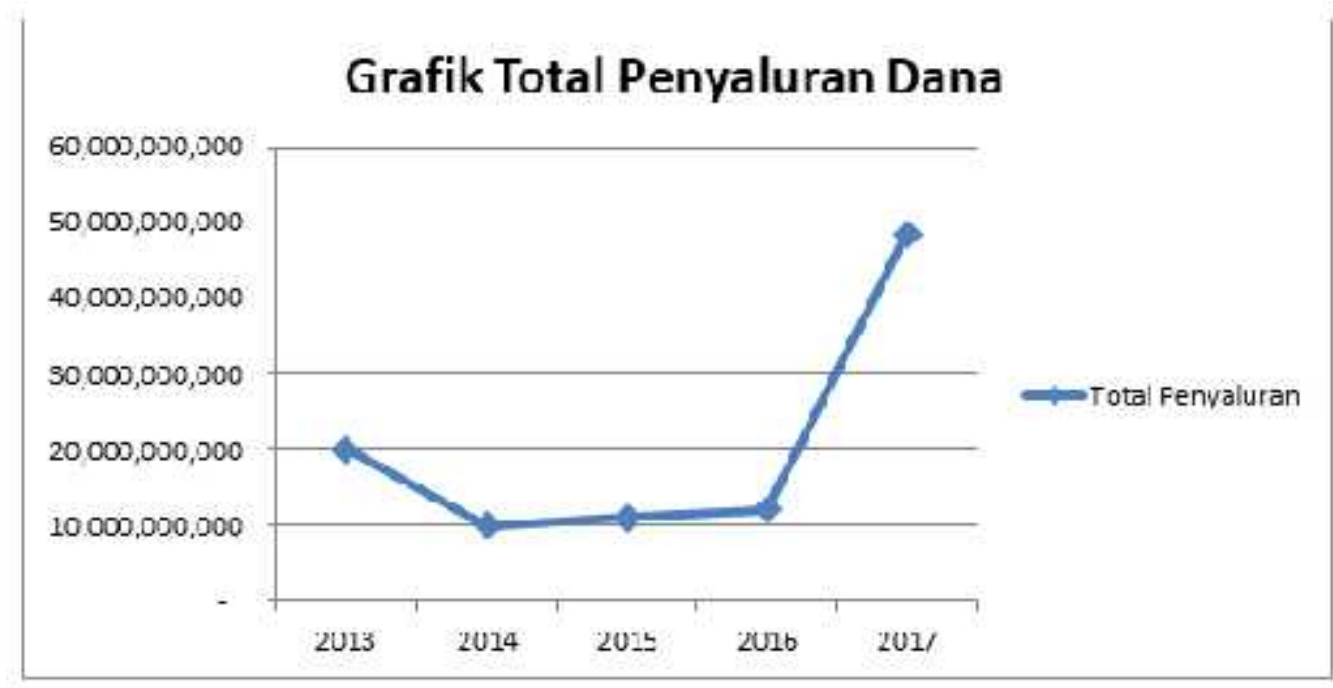

Pembiayaan tahun 2016 sejumlah Rp. 15.439.565.978,- dan pada tahun 2017 menjadi sejumlah Rp. 24.354.706.482,-atau naik sebesar 57,742\%, perkembangan tersebut dapat dilihat pada gambar 3:

Gambar 3

Pembiayaan

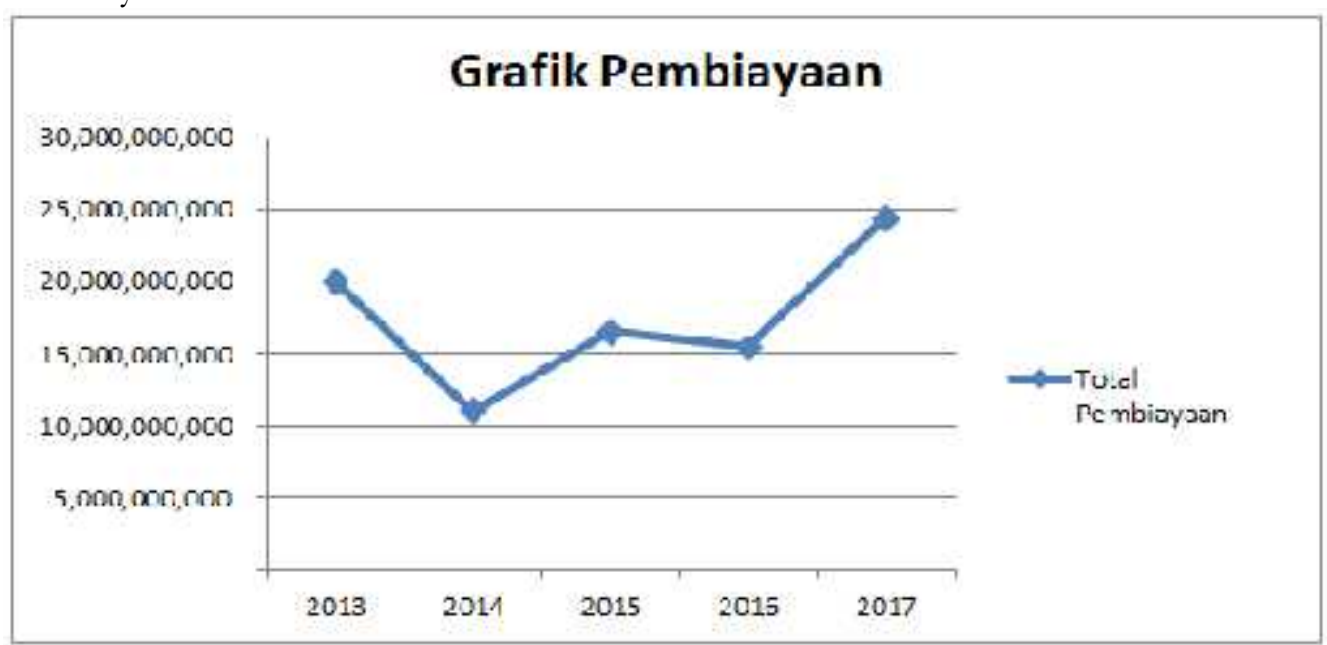


Perkembangan simpanan tahun 2016 sejumlah Rp. 13.044.020.244,- dan pada tahun 2017 meningkat sejumlah Rp. 15.007.547.217,- atau tumbuh 15,06\%. Perkembangan tersebut dapat dilihat dari gambar 4:

Gambar 4

Perkembangan Simpanan

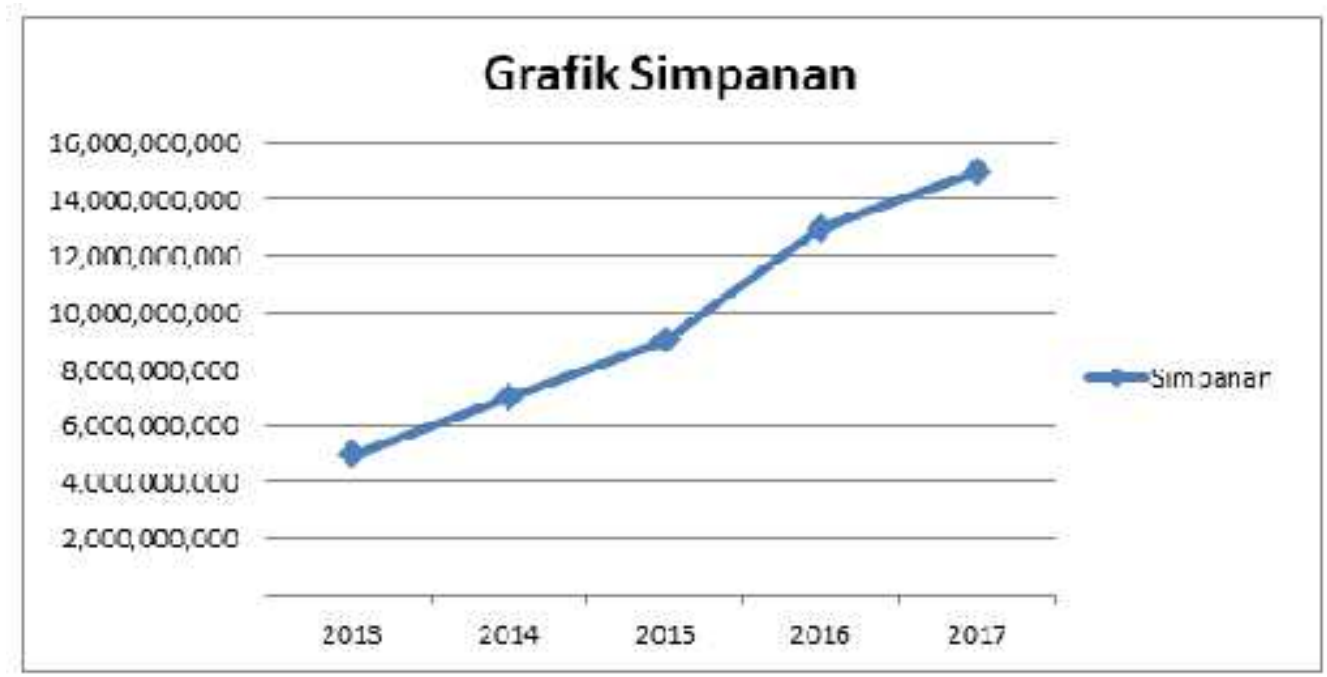

Perkembangan simpanan berjangka/IMB pada tahun 2017 mengalami pertumbuhan 178\% dari tahun sebelumnya (2016), perkembangan tersebut dapat dilihat dari gambar 5:

Gambar 5

Perkembangan Simpanan Berjangka

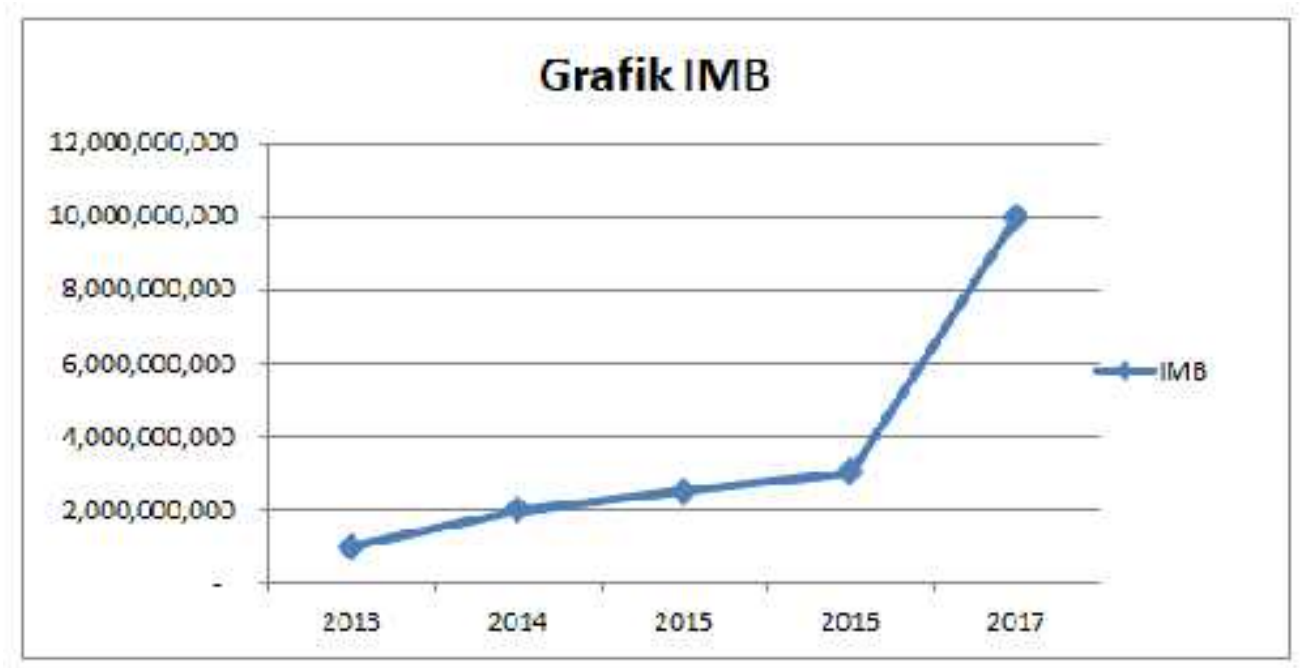


Perkembangan aset tahun 2016 sejumlah Rp 29.564.456.340,- dan pada tahun 2017 naik menjadi sejumlah Rp45.640.102.071,- atau tumbuh 54\%, perkembangan tersebut dapat di lihat dari gambar 6 :

Gambar 6

Perkembangan Asset

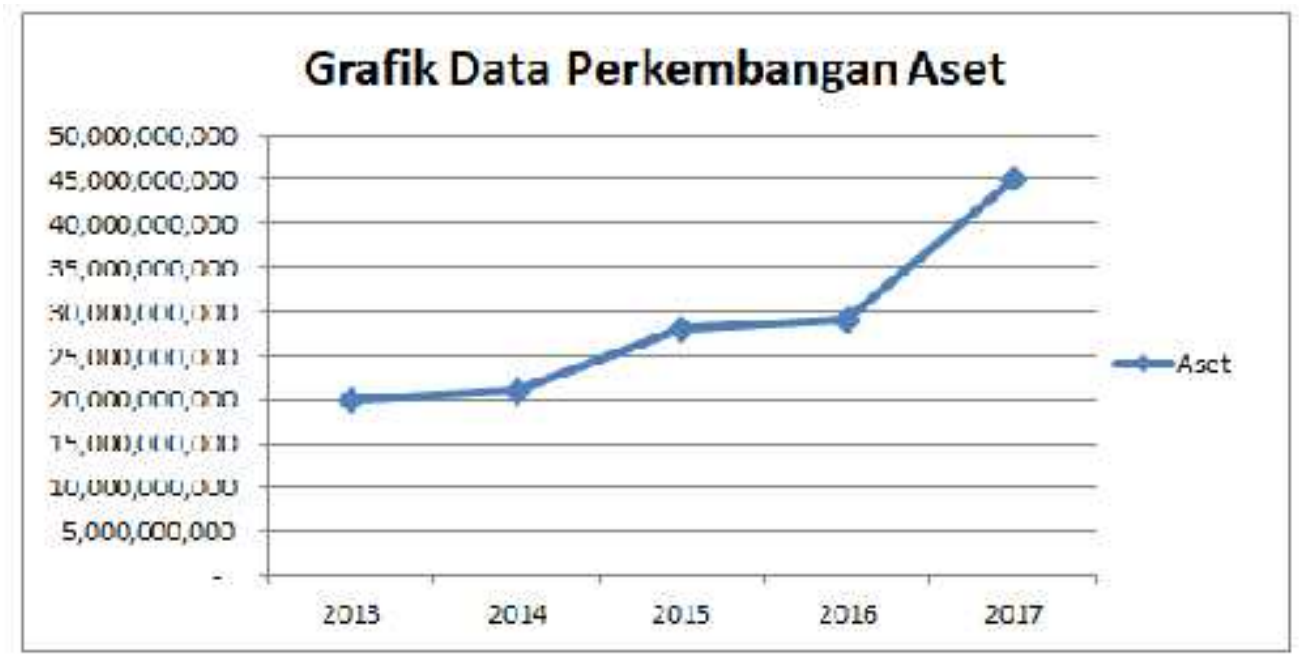

Total pinjaman pada pihak ketiga tahun 2016 sejumlah Rp. 7.499.791.079,- dan pada tahun 2017 menjadi Rp. 14.253.716.547,- atau naik 90\%, perkembangan pinjaman pihak ketiga dapat dilihat pada gambar 7 :

Gambar 7

Pinjaman Pihak Ketiga

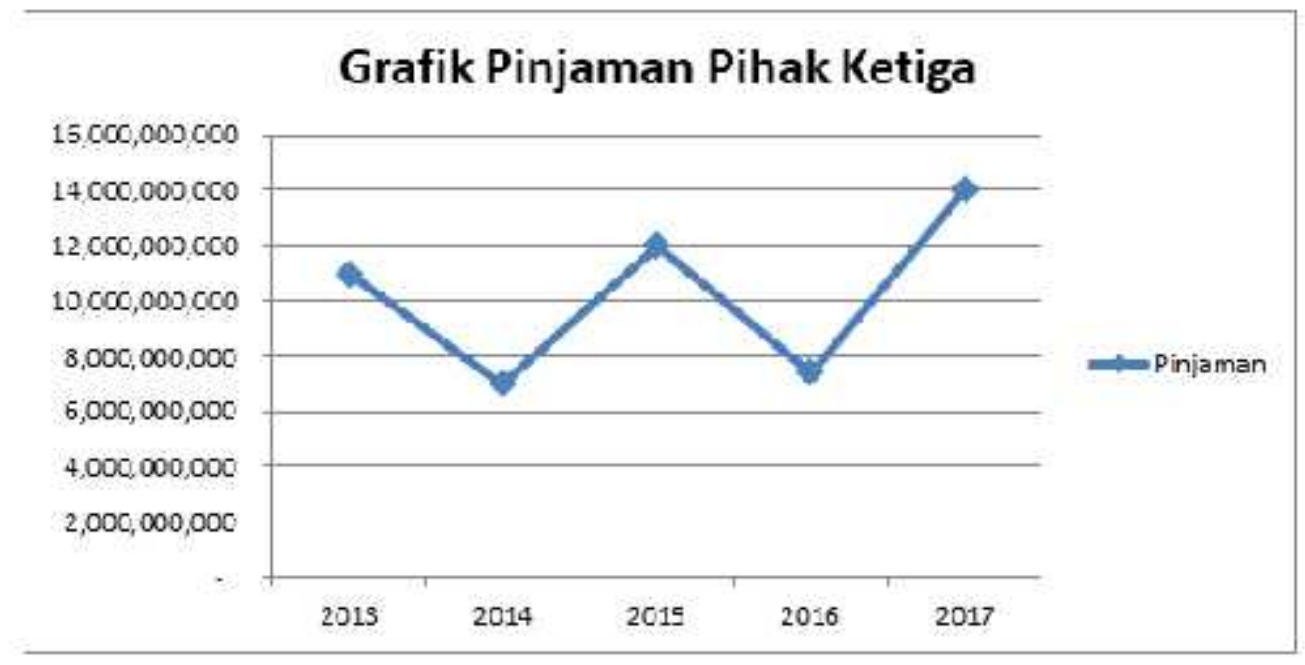

Pendapatan margin tahun 2016 sejumlah Rp. 3. 352.886.151,- dan pada tahun 2017 menjadi sejumlah Rp. 5.579.726.718,- atau naik 66\%, perkembangan margin dapat dilihat pada gambar 8: 
Gambar 8

Perkembangan Pendapatan



Gambar 9

Perkembangan SHU

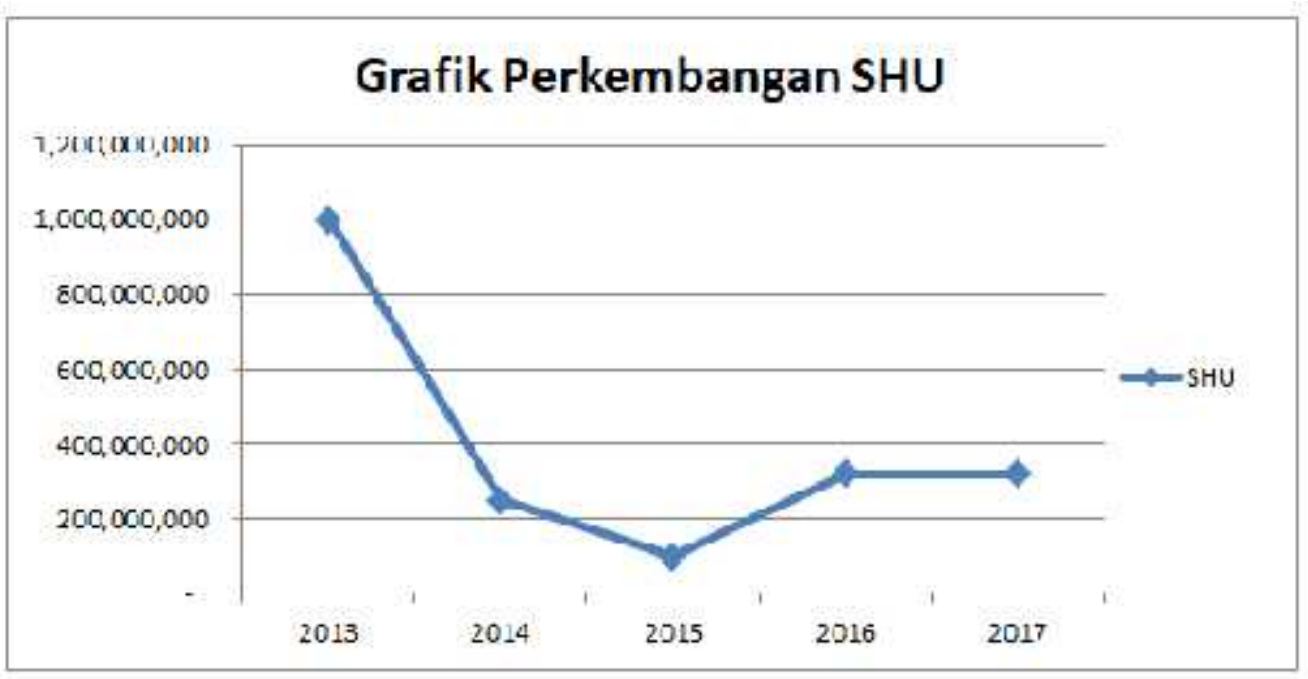

Pelayanan anggota dilakukan di kantor cabang dan kantor kas, dimana pengajuan pembiayaan dilakukan di kantor kas. Pelayanan anggota di kantor pusat dilakukan dari jam 07.30-17.00 WIB, sedangkan pelayanan di kantor kas yang berada di pasar-pasar biasanya hingga jam 14.00. Jumlah anggota sebanyak 8.565 orang dan calon anggota sebanyak 5.734 orang dilayani di 6 kantor cabang dan 15 kantor kas.

\section{Kinerja Keuangan}

Kinerja keuangan yang dicapai oleh BTM BiMU sebagai berikut: 
Tabel 1

Kinerja Keuangan

\begin{tabular}{clccccc}
\hline No & \multicolumn{1}{c}{ Rasio } & 2017 & 2016 & 2015 & 2014 & 2013 \\
\hline 1 & $\begin{array}{l}\text { Rasio Likuiditas } \\
\text { Current Ratio } \\
\text { (Aset lancar/ Utang lancar) }\end{array}$ & $98,18 \%$ & $86,79 \%$ & $35,18 \%$ & $20,09 \%$ & $24,47 \%$ \\
\hline 2 & $\begin{array}{l}\text { Rasio Leverage } \\
\begin{array}{l}\text { Debt to total asset } \\
\text { (Total utang/Total asset) }\end{array}\end{array}$ & $87,82 \%$ & $83,66 \%$ & $85,09 \%$ & $84,08 \%$ & $85,14 \%$ \\
\hline 3 & $\begin{array}{l}\text { Rasio Profitabilitas } \\
\text { ROA } \\
\text { (Laba bersih/Total asset) }\end{array}$ & $0,70 \%$ & 1,06 & 0,31 & 1,27 & $4,89 \%$ \\
\hline $\begin{array}{l}\text { ROE } \\
\text { (Laba bersih/Modal sendiri) }\end{array}$ & $5,76 \%$ & $6,48 \%$ & $2,06 \%$ & $7,95 \%$ & $32,91 \%$ \\
\hline
\end{tabular}

Keterangan :

1. Rasio likuiditas (liquidity ratio) adalah kemampuan suatu perusahaan memenuhi kewajiban jangka pendeknya secara tepat waktu.

2. Rasio leverage adalah mengukur seberapa besar perusahaan dibiayai dengan utang. Penggunaan utang yang terlalu tinggi akan membahayakan perusahaan karena perusahaan akan masuk dalam kategori utang ekstrem atau perusahaan terjebak dalam tingkat hutang yang tinggi dan sulit untuk melepaskan beban utang tersebut.

3. Rasio profitabilitas adalah mengukur efektivitas manajemen secara keseluruhan yang ditujukan oleh besar kecilnya tingkat keuntungan yang diperoleh dalam hubungannya dengan penjualan maupun investasi.

\section{PEMBAHASAN}

Pemberdayaan ekonomi masyarakat melalui amal usaha Muhammadiyah yaitu BTM BiMU Lampung, merupakan penyaluran pembiayaan untuk modal kerja dan bersifat saling menguntungkan. Modal BTM BiMU Lampung berasal dari modal sendiri dan modal luar dari pihak ketiga, sehingga perhitungan bisnis menjadi pertimbangan dalam pembiayaan modal kerja. Sasaran pemberdayaan ekonomi masyarakat terutama adalah pedagang atau pengusahamikro kecil.

BTM BiMU sebagai bagian dari Muhammadiyah melakukan pemberdayaan ekonomi masyarakat melalui pembiayaan produktif kepada masyarakat. Sasaran pembiayaan terutama di sektor perdagangan, dimana mencapai $80 \%$ dari total anggota maupun calon anggota (14.299 orang) dan 20\% disektor yang bervariasi. Dengan jumlah anggota maupun calon anggotamencapai 14.299 orang, bila diasumsikan tiap anggota memperkerjakan 2 orang maka sebanding dengan 28.598 orang yang bergantung pada BTM BiMU dan ini jumlah yang cukup besar. Sektor perdagangan yang banyak dibiayai berada di lingkungan pasar, sehingga BTM BiMU banyak memiliki kantor kas di pasar-pasar sesuai kantor cabang masing-masing. Selain itu, pembiayaan yang diberikan kepada anggota disesuaikan dengan besar kecilnya usaha yang dijalankan sehingga pembiayaan dengan plafon sebesar Rp 1.000.000,- masih diberikan. Prinsipnya semua pembiayaan dijamin dengan jaminan barang tertentu, dengan prinsip saling percaya. 
BTM BiMU memiliki 5 kantor cabang di 5 kabupaten/kota, 17 kantor kas dan kantor cabang pembantu untuk melayani 14.299 anggota dan calon anggota. Pemberdayaan Muhammmadiyah berbeda dengan yang ditampilkan oleh organisasi lainnya dimana dalam Muhammadiyah melalui pengkaderan dan melalui pembinaan kesadaran berekonomi secara syari'ah sehingga dapat mencapai keswadayaan dan kemandirian ekonomi. Sebagai koperasi primer, maka BTM BiMU langsung bersentuhan dengan anggota yang memiliki usaha yang bermacam-macam.

Strategi yang dijalankan oleh BTM BiMU antara lain :

1. Mendekatkan diri dengan masyarakat yang memiliki usaha dan perlu dana untuk mendukung usaha. Hal ini ditunjukkan dengan keberadaan kantor kas di pasar-pasar tradisional;

2. Bekerja sama dengan dengan sumber dana baik bank maupun non bank, agar dapat mendapatkan dana bagi kelangsungan usahanya;

3. Melakukan edukasi tentang ekonomi syari'ah kepada warga Muhammadiyah tentang pentingnya kemandirian ekonomi dan pentingnya berjamaah dalam ekonomi;

4. Memperluas jaringan kerja dengan membuka kantor cabang dan kantor kas;

5. Meningkatkan kerja sama dengan Muhammadiyah baik yang ada di tingkat wilayah maupun daerah sehingga keberadaannya lebih mudah dikenal;

6. Pembinaan dan pelatihan bagi anggota, karyawan maupun pengurus, sehingga kualitas sumber daya insani dapat meningkat.

Karena berbadan hukum koperasi, maka yang mendapatkan pelayanan hanya anggota dan calon anggota, sehingga bagi warga masyarakat mendapatkan pelayanan maka harus terdaftar sebagai calon anggota.

Berdasarkan data laporan RAT BTM BiMU tahun 2017, perbandingan piutang dan pembiayaan ( $\mathrm{Rp}$ 21.211.487.163,-) dengan biaya dibayar dimuka (Rp 2.401.542.140,-) sebesar 89,82 \% berbanding 10,17\% dari total Rp 23.613.029.303,-. Dari data tersebut terlihat bahwa biaya dibayar dimuka mencapai 5,26 \% dari total asset (Rp 45.640.102.071,-) atau bila dibandingkan dengan asset lancar (Rp 29.004.658.215,-) yang ada mencapai 8,28 $\%$.

Jumlah biaya dibayar dimuka yang sangat besar ini berarti sumber dana yang diakses oleh BTM BiMU Bandar Lampung masih kurang efektif dan tidak produktif. Dimana pada tahun 2016, biaya dibayar dimuka mencapai Rp 1.246.723.562,- dan tahun 2017 sebesar Rp 2.401.542.140,- mengalami peningkatan sebesar Rp 1.154.818.578,- atau $192 \%$. Berdasarkan data dari jumlah kewajiban baik jangka pendek dan panjang tahun 2017 sebesar Rp 40.082.643.507, - dengan jumlah kas dan setara kas sebesar Rp 2.640.992.786,dari jumlah total asset (Rp 45.640.102.071,-), maka diperkirakan bahwa kalau terjadi kondisi tertentu dimana anggota BTM melakukan penarikan simpanan, maka BTM tidak dapat memberikan pembiayaan likuiditas yang bersifat jangka pendek. Pada umumnya, anggota BTM/BMT menyimpan dananya bersifat jangka pendek dan biasanya menjelang hari raya idul fitri simpanan tersebut diambil bersamaan. Kondisi tersebut menyebabkan BTM/BMT kesulitan menyediakan uang tunai dan apabila jumlahnya besar, peranan BTM untuk membantu likuiditas anggota juga sangat terbatas. Hal ini terlihat dari laporan neraca keuangan tahun 2017 terutama kas dan setara kas tersedia.

Sedangkan sumber pendapatan BTM BiMU Bandar Lampung berasal dari piutang dan pembiayaan, persediaan, dan penyertaan. Pada tahun 2017 pendapatan usaha sebesar Rp 5.579.726.718,- dan pada tahun 2016 sebesar Rp 3.352.886.151,-, sedangkan pendapatan diluar usaha tahun 2017 sebesar Rp 547.368.897,- dan tahun 2016 Rp 731.998.0051. 
Jumlah total asset tertinggi dicapai tahun 2017 sebesar Rp 45.640.102.071,- dan mengalami kenaikan dibanding tahun 2016 yang sebesar Rp 29.564.456.340,- atau naik sebesar Rp 16.075.645.731,--. Saat ini dana pihak ke 3 BTM BiMU berasal dari Bank Mandiri Syariah, PT Telkom Indonesia dan LPDB serta UMI.

Dengan outstanding tahun 2017, pembiayaan dari Bank Mandiri Syariah sebesar Rp 11.246.875.054,-, pembiayaan dari PT Telkom Indonesia sebesar Rp 159.791.540,- dan LPDB sebesar Rp 408.724.200,-. Serta UMI sebesar Rp 2.438.325.753,-. Total outstanding pembiayaan yang diterima tahun 2017 sebesar Rp 14.265.785.154,- dan tahun 2016 sebesar Rp 7.499.791.079,--.

Berdasarkan laporan neraca tahun 2017, BTM BiMU memiliki total asset sebesar Rp 45.640.102.071,-, dan memiliki asset tidak lancar mencapai Rp 16.635.443.857,- dan piutang yang hanya mencapai Rp 21.211.487.163,-, Dari data tersebut, berarti asset yang produktif hanya $46,47 \%$., hal ini berakibat masih rendahnya sisa hasil usaha yang hanya sebesar Rp 320.298.997,- atau 0,70\% dibanding total asset. Kinerja keuangan BTM BiMU masih belum memuaskan dan harus ditingkatkan, terkait asset yang tidak produktif perlu dievaluasi lebih lanjut. Untuk meningkatkan kinerja keuangan pada BTM BiMU maka disarankan untuk mengevalusi dan menyelesaikan asset tidak lancar yang mencapai $\mathrm{Rp}$ 16.635.443.857,-, terutama penyertaan kepada pihak ke 3, asset tetap baik berupa tanah dan bangunan.

\section{KESIMPULAN}

1. Pelayanan pembiayaan BMT BiMU Bandar Lampung kepada pelaku usaha didominasi di sektor perdagangan mencapai $80 \%$ dari 14.299 anggota dan berada di pasar-pasar tradisional terutama usaha yang produktif;

2. BTM BiMU Bandar Lampung belum dapat memenuhi kebutuhan anggota secara maksimal terutama likuiditas di hari raya idul fitri.

3. Kinerja keuangan BTM BiMU dilihat Current ratio, leverage ratio, profitabilitas ratio hasilnya kurang bagus.

Diharapkan BTM BiMU perlu meningkatkan edukasi dan pelayanan kepada anggota sehingga anggota dapat mandiri secara ekonomi dan kinerja keuangannya harus dievaluasi sehingga dapat memberikan keuntungan yang signifikan.

\section{REFFERENSI}

Ayi Sobarna. Konsep Pemberdayaan Ekonomi Bagi Masyarakat Miskin Perkotaan. Jurnal Mimbar VolumeXIXNo.3Juli-September2003:316-329. Universitas Islam Bandung.

Badan Pusat Statistik Kota Bandar Lampung. 2017. Kota Bandar Lampung Dalam Angka 2016.

Fikma, Bram. 2013. Amal Usaha Ekonomi Muhammadiyah. http://bramfikma.blogspot.co.id/2013/03/amal-usaha-ekonomi-

muhammadiyah.html Jumat, 29 Maret 2013 Diakses tgl 27 Juni 2016 jam 12:01

Ghony, M. Djunaidi dan Almanshur, Fauzan. 2012. Metodologi Penelitian Kualitatif, Yogyakarta: Ar-Ruzz Media. http://btmbimu.id

Idrus, Muhammad. 2007. Metode Penelitian Ilmu-Imu Sosial (pendekatan Kualitatif \& Kuantitatif, Yogyakarta: UII Press.

Kurniawati, Dwi Pratiwi; Supriyono, Bambang dan Hanafi, Imam. 2013. Pemberdayaan 
Masyarakat di Bidang Usaha Ekonomi (Studipada Badan PemberdayaanMasyarakat Kota Mojokerto). JurnalAdministrasi Publik(JAP),Vol.I,No.4,Hal9-14. Malang : Universitas Brawijaya.

Manurung,Laurensius. 2010. Strategi dan inovasi model bisnis meningkatkan kinerja usaha: studi empiris industry penerbangan Indonesia.Jakarta : Elex Media Komputindo.

Mardikanto, Totok dan Soebianto, Poerwoko. 2015. Pemberdayaan Masyarakat dalam Perspektif Kebijakan Publik. Bandung : Alfabeta.

Muhammad, Jamaluddin. Macam-macam amal usaba Muhammadiyah, 2013 http://www.belajarnya.com/2016/06/macam-macam-amal-usahamuhammadiyah. html\#more

Rahadi, Dedi Rianto. (2010). Manajemen Kinerja Sumber Daya Manuasia. Malang: Tunggal Mandiri Publishing.

Simanjuntak, Payaman. 2005. Evaluasi kinerja. Informasi Hukum Vol. 2 Tahun VII, 2005. http://membangun-sdm.blogspot.co.id/2008/10/evaluasi-kinerja.html Diakses 27 Juni 2017 20:01 WIB

Sumodiningrat,Gunawan.(1999). Pemberdayaan Masyarakat dan Jaring Pengamanan Sosial. Yogyakarta: GhaliaIndonesia.

Suryawan, Nasrul wahyu. 2013. Program organisasi Mubammadiyah dalam membangun Nilai Toleransi sebagai upaya menghadapi perbedaan paham pada masyarakat di Kabupaten Ponorogo, Jurnal Pendidikan kewarganegaraan Universitas Negeri Malang, vol 2, No. 1, 2013. http://jurnal-online.um.ac.id/data/artikel/artikelD4EDB98236A38C670118AE 52C23F525D.pdf Diakses 27 Juni 2017 20:20 WIB

Ruslan, Ismail. 2012. Pemberdayaan ekonomi masyarakat berbasis masjid di Pontianak. Jurnal Khatulistiwa - Journal OfIslamic Studies, Volume2 Nomor 1Maret 2012. STAIN Pontianak

Ridwan, Mochamad (2012). Penguatan ekonomi masyarakat berbasis kelompok. JurnalEkonomiPembangunan Volume13, Nomor2,Desember2012, hlm.207-217. Universitas Bengkulu.

Wayan Siti, dkk. 2011. Pemberdayaan ekonomi kerakyatan berbasis masyarakat adat di kecamatan Bebanden kabupaten Karangasem, Bali. Majalah AplikasiIpteksNgayah,2(2),2011,78-88. Universitas Udayana

Zamzami, Lucky. 2011. Pemberdayaan Ekonomi Masyarakat Pesisir di Nagari Ampiang Perak, Sumatera Barat. Jurnal Mimbar,Vol.XXVII,No.1(Juni2011):113-125. Universitas Islam Bandung. 